\title{
Immune Response to BCG Vaccination in Children
}

\author{
by Sarala Rajajee, MD and P. R. Narayanan, ${ }^{*} \mathrm{PhD}$ \\ Research Fellow, Madras Medical College, Madras \\ * Head of Department of Immunology, TB Research Centre, ICMR, Madras
}

The world-wide programme of mass BCG vaccination started in $1921^{1}$ and used extensively since the forties has provided evidence that BCG vaccine has a protective value. This was confirmed by studies done on experimental animals. ${ }^{2}$ Despite this, no vaccination has become more controversial than BCG vaccination in recent times. The protection conferred by $B C G$ vaccination in children is important because of the serious consequences of tuberculosis in them.

The aim of this study was to assess the immunological response of children to BCG vaccination.

\section{Materials and Methods}

The study group consisted of children of employees of a private company attending a medical centre established for the benefit of the workers. The average income of the families was Rs. $800 /-$ to Rs. 1000/- per month. During a screening programme for tuberculosis among all the employees and their families, 90 tuberculin negative normal children were vaccinated by the BCG team from the Government Chest Institute, Chetput, Madras. $0.1 \mathrm{ml}$ containing $0.1 \mathrm{mg}$ of BCG was administered.

Normal BCG reaction occurred after 4-6 weeks and healed after 1-2 months leaving an easily identifiable scar. Post vaccination allergy was tested in 15 children 6 months later and in 50 children 1 year later using PPD-S 1 tuberculin unit with Tween 80 (BCG Laboratories, Guindy) by the intracutaneous method (Mantoux). All the recommended precautions were taken to avoid false negative tests. ${ }^{3.4}$

With the consent of the parents, all the 50 were tested for reaction to 2,4 dinitrochlorobenzene (DNCB) using the method of Catalona et al..$^{5}$ but with the lower sensitizing dose of $500 \mu \mathrm{g}$ as this was found to be as effective as $1000 \mu \mathrm{g} .^{6}$ The results were expressed as negative for no response to $4+$ for very strong reaction.

\section{Acknowledgement}

Sarala Rajajee was a recipient of an Indian Council of Medical Research Senior Research Fellowship during the period of this research. The authors are grateful to the Director, TB Research Centre for permission to do this work.

Address for correspondence: Dr S. Rajajee. 19 II Main Ruad, C.I.T. Colony, Madras, India 600004.
Fourteen children, all of whom were Mantoux negative, were tested for the lymphocyte response to phytohemagglutinin (PHA) and the antigens PPD and BCG. They were tested in parallel with controls. Ten of the controls had received BCG and were Mantoux positive; 8 controls had not been given BCG and were Mantoux negative. ${ }^{7,8}$

The immunological studies were done at the Immunology Department, Tuberculosis Research Centre (ICMR), Ghetput, Madras.

\section{Lymphocyte transformation test (LTT)}

Peripheral blood lymphocytes were isolated by Ficoll-Hypaque density gradient centrifugation. Cells were cultured in triplicate in $0.2 \mathrm{ml}$ of RPMI 1640 supplemented with penicillin $(100 \mu / \mathrm{ml})$ streptomycin $(100 \mu \mathrm{g} / \mathrm{ml})$ glutamine $(300 \mu \mathrm{g} / \mathrm{ml})$ and 10 per cent autologous plasma in 96 well (u bottom) tissue culture plates (Laxbro) at a concentration of $0.5 \times 10^{6}$ cells $/ \mathrm{ml}$ PHA was added to a final concentration of $1 \mu \mathrm{g} / \mathrm{ml}$, PPD $50 \mu \mathrm{g} / \mathrm{ml}$ and BCG $50 \mu \mathrm{g} / \mathrm{ml}$. Cultures were incubated at $37^{\circ} \mathrm{C}$ in 5 per cent $\mathrm{CO}_{2}$ for 96 hours for PHA and 144 hours for PPD and BCG. The cultures received $1 \mathrm{uCi}$ of $3 \mathrm{H}$ Thymidine $(\mathrm{Sp}$. act $13000 \mathrm{mCi} / \mathrm{mol}$ Babha Atomic Research Centre, Bombay) 16 hours before harvesting.

Cells were harvested with MASH II (Microbiological Associates USA) and deposited on fibre glass filter paper. Paper discs were then transferred to biovials containing $1 \mathrm{ml}$ of scintillation fluid and counted in a $\beta$ scintillation counter. (Packard Tricarb 300) Stimulation Index was calculated as follows:-

$$
\frac{\text { CPM in stimulated cultures }}{\text { CPM in control cultures. }}
$$

\section{Indirect leucocyte migration inhibition test (ILMI)}

Lymphokines; Lymphocytes were cultured in sterile Bijou bottles at a concentration of $1 \times 10^{6}$ cells $/ \mathrm{ml}$. In RPMI 1640 with Penicillin $100 \mu / \mathrm{ml}$ Streptomycin $100 \mu \mathrm{g} / \mathrm{ml}$ Glutamine $300 \mu \mathrm{g} / \mathrm{ml}$ along with 10 per cent sterile horse serum. The cells were stimulated using PPD $50 \mu \mathrm{g} / \mathrm{ml}$ and BCG $50 \mu \mathrm{g} / \mathrm{ml}$ with controls to which no antigen was added. The cultures were incubated at $37^{\circ} \mathrm{C}$ in 5 per cent $\mathrm{CO}_{2}$ for 5 days. After centrifugation, the supernatant containing lymphokines, was separated and frozen at $-20^{\circ} \mathrm{C}$ until use. 


\section{Guinea pig macrophages}

Liquid paraffin $10 \mathrm{ml}$ was injected intraperitoneally into guinea pigs. After 3 days, the peritoneal cells were collected and washed thrice with Hank's BSS. After the final washing, the cells were suspended in $0.1 \mathrm{ml}$ of RPMI 1640 , micro capillaries were filled with the cell suspension and one end sealed. The capillary tubes were centrifuged to pack the exudate cells. The capillaries were then cut at the cell fluid interface.

The exudate cells were shown to migrate in 12 well LM 1 plates (Laxbro) in the presence of lymphokines obtained from the children. The plates were incubated at $37^{\circ} \mathrm{C}$ for 18 hours. Migration patterns were projected at fixed magnification and traced. The projected areas were measured by cutting out and weighing. The assay was set up in triplicates. The results were expressed as migration index.

\section{Migration index (MI)}

area of migration in the presence of lymphokines of stimulated lymphocytes

$=$

area of migration in the presence of lymphokines of control lymphocytes.

Migration index of less than 0.8 was taken as indicative of positive reactors.

\section{Results}

The average age of the children was 6.5 years.

There were 28 boys and 22 girls. Forty of the 50 children were of normal weight for age and 10 had grade 1 under nutrition (Table 1).

TABLE 1

Nutritional status of 50 children graded using weight for age Gomez method of classification and ICMR reference standards

\begin{tabular}{ccccc}
\hline Number & Normal & Grade I & Grade II & Grade III \\
\hline 50 & 40 & 10 & - & - \\
\hline
\end{tabular}

TABLE 2

Mantoux conversion after $B C G$

\begin{tabular}{|c|c|c|c|c|}
\hline \multirow{2}{*}{$\begin{array}{l}\text { No. of } \\
\text { children }\end{array}$} & \multirow{2}{*}{$\begin{array}{c}\text { Mantoux } \\
\text { before } \\
\text { BCG } \\
<5 \mathrm{~mm}\end{array}$} & \multicolumn{3}{|c|}{ Mantoux 1 year after BCG } \\
\hline & & $<5 \mathrm{~mm}$ & $5-10 \mathrm{~mm}$ & $>10 \mathrm{~mm}$ \\
\hline \multirow[t]{3}{*}{50} & 50 & 45 & 2 & 3 \\
\hline & & \multicolumn{3}{|c|}{ Mantoux 6 months after BCG } \\
\hline & & $<5 \mathrm{~mm}$ & $5-10 \mathrm{~mm}$ & $>10 \mathrm{~mm}$ \\
\hline 15 & 15 & 15 & - & - \\
\hline
\end{tabular}

* PPD-S
Table 2 indicates that 45 out of 50 children ( 90 per cent) were non-converters with post-vaccination allergy of less than $5 \mathrm{~mm}$. Five children showed reactions more than $5 \mathrm{~mm}$ in size of whom 3 had reactions more than $10 \mathrm{~mm}$ in size after BCG. All the 15 children tested at 6 months were tuberculin negative.

All the 50 children displayed normal cutaneous hyper-sensitivity to DNCB with majority having 3 plus and 4 plus reactions. Nine of them also had good response to PPD. This was significant when compared to non-vaccinated mantoux negative controls (Tables 3 and 4, Fig. 2).

Indirect leucocyte migration inhibition test also showed good response to antigens PPD and BCG in 13 out of 14 children (Table 5, Figs 3 and 4). This was highly significant when compared to the response in non-vaccinated tuberculin negative children.

TABLE 3

ITU with TWEEN 80

\begin{tabular}{ccccc}
\hline \multirow{2}{*}{ Mantoux } & $\begin{array}{c}\text { Number } \\
\text { of } \\
\text { children }\end{array}$ & 2 plus & 3 plus & 4 plus \\
\cline { 3 - 5 } & $(45)$ & 2 & 28 & 15 \\
$<5 \mathrm{~mm}$ & $(4)$ & - & 1 & 1 \\
$5-10 \mathrm{~mm}$ & $(2)$ & - & 2 & 1 \\
$>10 \mathrm{~mm}$ & $(3)$ & - & & \\
\hline
\end{tabular}

TABLE 4

Lymphocyte transformation response to PPD

\begin{tabular}{lcc}
\hline \multicolumn{1}{c}{ Group } & No. & $\begin{array}{c}\text { Stimulation index } \\
\text { Mean and S.D. }\end{array}$ \\
\hline $\begin{array}{l}\text { BCG vaccinated } \\
\begin{array}{l}\text { Mantoux negative } \\
\text { Non-vaccinated }\end{array}\end{array}$ & 9 & $2.8 \pm 2.24^{*}$ \\
Mantoux negative & 8 & $0.9 \pm 0.6$ \\
\hline
\end{tabular}

* Highly significant $P<0.05$.

TABLE 5

ILMI in vaccinated and non-vaccinated group

\begin{tabular}{lccc}
\hline \multicolumn{1}{c}{ Group } & No. & $\begin{array}{c}\text { Migration } \\
\text { PPD }\end{array}$ & $\begin{array}{c}\text { Index mean, } \\
\text { S.D. BCG }\end{array}$ \\
\hline $\begin{array}{l}\text { BCG vaccinated } \\
\text { children } \\
\text { tuberculin negative }\end{array}$ & 14 & $0.4 \pm 0.3$ & $0.6 \pm 0.06^{*}$ \\
$\begin{array}{l}\text { Non-vaccinated } \\
\text { children } \\
\text { tuberculin negative }\end{array}$ & 3 & $1.5 \pm 0.2$ & $1.2 \pm 0.4$ \\
\hline
\end{tabular}

* Highly significant $P<0.001$.

Journal of Tropical Pediatrics No. $31 \quad$ April 1985 


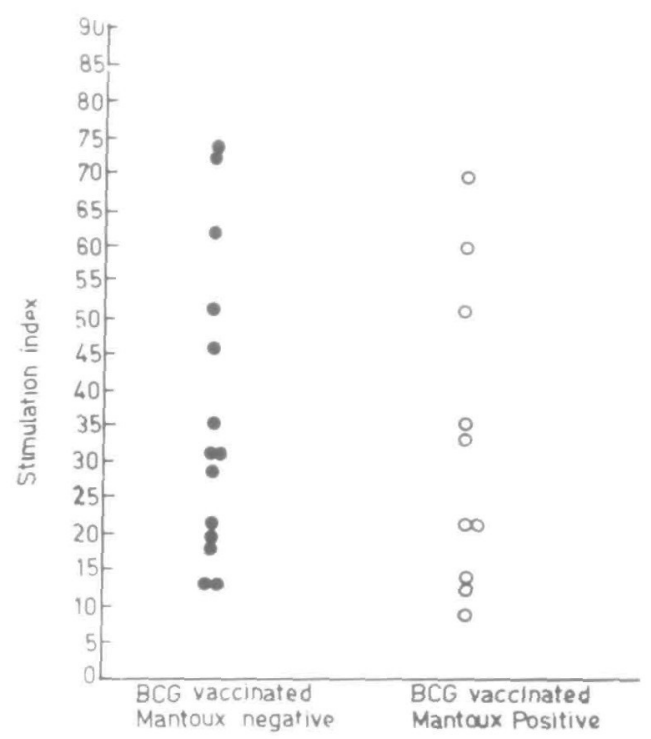

Fig. 1. Lymphocyte transformation response to PHA-P.

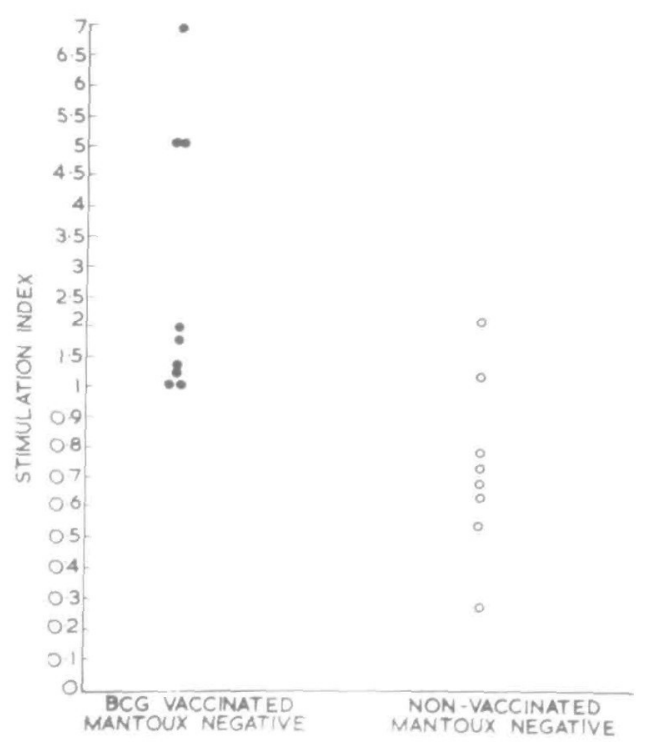

FIG. 2. Lymphocyte transformation response to PPD.

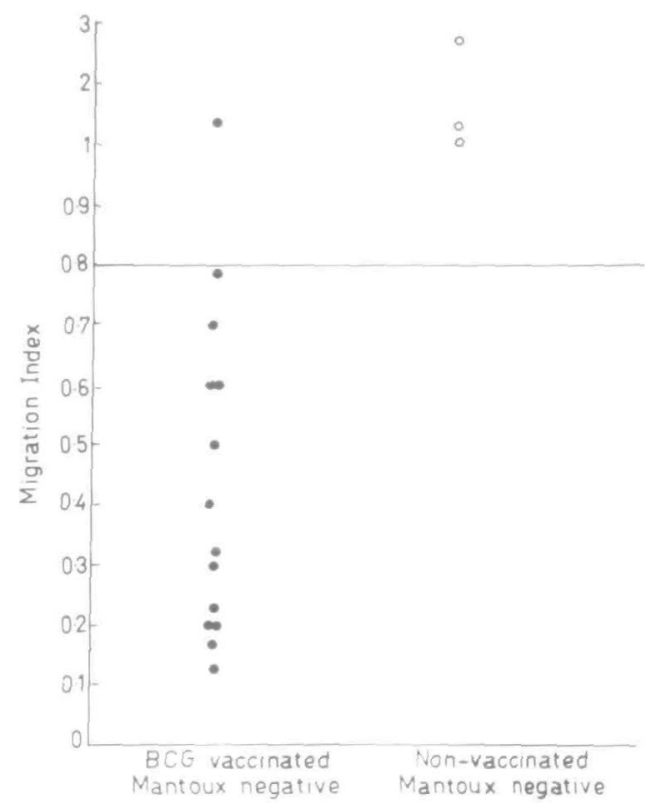

FIG. 3. Indirect leucocyte migration inhibition response to PPD.

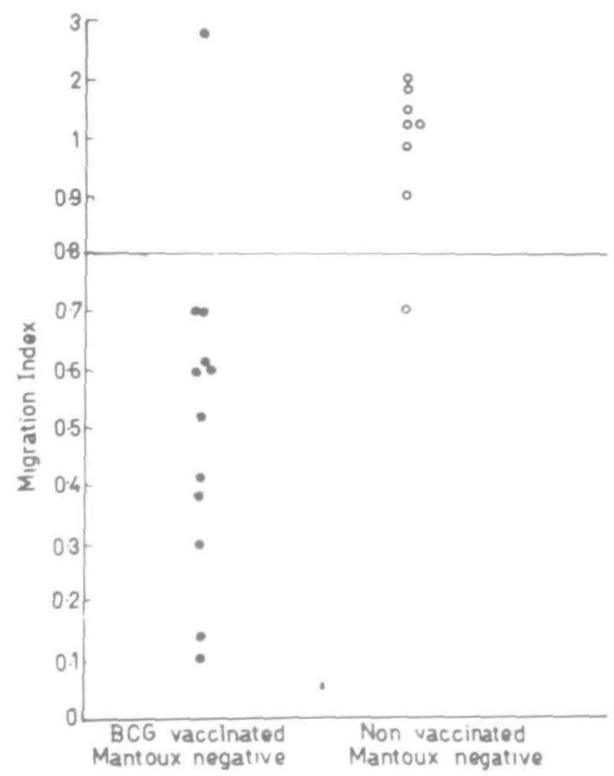

FIG. 4. Indirect leucocyte migration inhibition response to $\mathrm{BCG}$ 


\section{Discussion}

The protective value of BCG vaccine is controversial, controlled field trials have shown protection to range from none to as much as 80 per cent.

For measuring the degree of resistance against tuberculosis conferred by vaccination, Moller suggested that PVA can be accepted as indirect evidence of immunity. ${ }^{10}$ Miller considered BCG vaccination to be successful if it produced a positive tuberculin reaction. ${ }^{11}$

The tuberculin test shows a high degree of negative reactions even in the presence of tuberculosis or after $B C G$ vaccination and total reliance on PVA as a means of evaluating response to BCG will give misleading results regarding the value of $\mathrm{BCG}$ vaccination. ${ }^{12-15}$

Ninety per cent of the children in the present group were tuberculin negative at 1 year and 15 were negative even earlier at 6 months. Clinically, majority of the children were nutritionally normal for their age and came from middle income group families.

Cell mediated immunity (CMI) was normal as shown by positive DNCB skin reactions in all and good response to PHA in LTT.

In vitro tests showed significant positive response of the lymphocytes to PPD and BCG both in LTT and ILMI tests. This points to the presence of immunocompetent $T$ cells in the absence of positive skin test.

This was also found in a study to assess the efficacy of BCG given at birth compared to at age 3 months by Mantoux skin test and lymphocyte migration inhibition (LMI) test. ${ }^{16}$ In vitro positive cell mediated response was found even after the positive skin tests became negative. ${ }^{17}$ Positive LMI response was recorded in 87.6 per cent of pre-school children after BCG vaccination in the newborn period irrespective of their nutritional status. ${ }^{18}$ In a study on undernourished children it was found that though Mantoux was negative in children with kwashiorkor, LMI response to PPD was positive in these children. ${ }^{19}$

These results indicate that a negative skin test does not imply absence of in vitro CMI response. ${ }^{20-22}$ Oppenheim ${ }^{23}$ observed that in vitro response can occur before the development of reactive skin tests in persons vaccinated with BCG. He speculated that fewer immunologically committed lymphocytes might be needed to produce an in vitro response. The available circulating pool of tuberculin committed lymphocytes might not have been of sufficient magnitude to produce a local reaction in the skin but were adequate to produce an in vitro response. In our study, the non-vaccinated children who were Mantoux negative did not show positive Lymphocyte responsiveness to tubercular antigens in the in vitro tests. But, the BCG vaccinated group who remained Mantoux negative did show lymphocyte sensitivation to these antigens. We conclude that BCG vaccination induces positive immune response in children.

\section{Summary}

Ninety children attending a medical centre were administered the BCG vaccine after initial negative tuberculin reaction with 1 tuberculin unit (TU) of PPD-S. Fifty children were tested for post vaccination allergy (PVA) at one year, of whom 15 children were also tested at six months. Ninety per cent of the 50 children showed negative reaction to PPD-S $(<5 \mathrm{~mm})$ at 1 year, only 10 per cent had a positive reaction. All the 50 children had positive response to 2,4 dinitrochlorobenzene (DNCB) indicating normal delayed cutaneous hypersensitivity.

Fourteen children who were negative reactors after BCG showed normal response to phytohemagglutinin (PHA) in the lymphocyte transformation test (LTT) indicating normal cell mediated immune response (CMI). They all had significant response to PPD and BCG in indirect leucocyte migration inhibition test (ILMS). The stimulation index in the lymphocyte proliferative response to PPD was $2.8 \pm 2.24$ in these children.

Thus, in vitro tests indicate that the $T$ lymphocytes were sensitised to PPD and BCG after BCG vaccination even though tests for post vaccination allergy were negative. This was significant as 8 nonvaccinated tuberculin negative children did not show evidence of lymphocyte sensitisation to PPD and BCG.

\section{References}

1 Suri JC, Khanna KK. BCG vaccine. In: Rao RN, ed. Text Book of tuberculosis. Vikas Publishing House Limited 1981, 534-42.

2. Smith DW, Haudung GE. Current strains of BCG protection in animals. WHO/TB/80: 111 (Technical communication), 1980.

3. Goth GD. Tuberculin testing in clinical medicine. Indian Pediatr 1982; 19: 1013-20.

4. Udani PM. Evaluation of tuberculin test in clinical practice. Indian Pediatr 1982; 19: 469-86.

5. Catalona WJ, Taylor PT, Robson AS, Chretein PB. Contact sensitisation. N Engl J Med 1972; 286: 399-402.

6. Rajajee S, Narayanan PR. Under publication.

7 Mehra S, Man M, Ghosh S. A study of tuberculosis infection and disease among healthy rural school children near Delhi. Indian J Med Res 1979; 70: 697-701.

8. Ghosh S, Rao VS, Berry AM, Man M. Tuberculin conversion in apparently heal thy children and its implications in chemotherapy of tuberculin positive children. Indian J Med Res 1977; 65: 640-7.

9. Ten Dam HG, Toman K, Hitze KL, Guld J. Present knowledge of immunisation against tuberculosis. Bull WHO 1976; 54: 255-69.

10. Moller H, quoted by Lin HT, Hyg SM. A study of the 
effect of simultaneous vaccination with BCG and smallpox in newborn infants. Bull WHO 1965; 33: 333-36.

11. Miller JW. BCG vaccination. In: Tuberculosis in children. Churchill Livingstone, 1982, 55-12.

12. Singhi S, Walia BNS. Tuberculosis-the diagnostic challenge. Indian Pediatr 1981; 18: 279-81.

13. Stuner $\mathbf{P}$, Rao $\mathbf{M}$, Vutana $\mathbf{M S}$, Labbantt Steiner $\mathbf{M}$. Persistently negative tuberculin reactors. Am J Dis Child 1980; 134: 747-50.

14. Smith AJ, Reichman BC. Lymphocyte transformation an aid in the diagnosis of tuberculosis in patients with non reactive skin tests. Am Rev Resp Dis 1972; 106: 194-7.

15. Verma IC, Gupta ML, Ghai OP. Evaluation of in vitro lymphoblastoid transformation in presence of purified protein derivative as diagnostic test in tuberculosis. Indian Paediatr 1974; 11: 339-44.

16. Sinclair S, Seth V, Arora NK, Arora HS, Kathipn K. Papers presented at Plenary session on BCG at Bangalore XVII National Conference of IAP, 1980.
17. Aroute GR. BCG induced tuberculin sensitivity and its lack of relevance for BCG revaccination. From Bibliography of immunisation, 1981 International Children's Centre Paris 9/5.

18. Indian Council of Medical Research Annual Report of the Director-General 1980-1981, 87-8.

19. Satyanarayana K, Bhaskaran P, Chitti Seshu V, Vinodhini $R$. Influence of nutrition on post-vaccinal tuberculin sensitivity. Am J Clin Nutr 1980; 33: 2334-7.

20. Kent DC, Schwartz R. Active pulmonary tuberculosis with negative tuberculin skin reaction. Am Rev Resp Dis 1967; 95: 411-18.

21. McFarland W, Heilman D. Comparison of lymphocyte transformation and intradermal reactions to tuberculins. Am Rev Resp Dis 1966; 93: 742-8.

22. Kerby GR. Correlation of tuberculin skin reaction with in vitro lymphocyte transformation, Am Rev Resp Dis 1968; 97: 904-8.

23. Oppenheim JJ. Relationship of in vitro lymphocyte transformation to delayed hypersensitivity in guinea pigs and man. Fed Proceedings 1968; 27: 21.

\title{
Osmolality of Rice Water, Dextrose-Saline Solution and Formula Milk-Implication in the Management of Infantile Gastroenteritis
}

\author{
by T. F. HO, MB, BS (Singapore), MMed(Anaes) (Singapore)', W. C. L. Yip, MB, BS (Singapore), \\ MMed(Paed) (Singapore), MRCP(UK), DCH(Lond), AM ${ }^{\text {b }}$ J. S. H. Tay, MB, BS(Sydney), MMed(Paed) \\ (Singapore), MD (Singapore, FRACP), AMc and H. B. Wong, MB, BS(Malaya), FRCP(Edin), FRCP(Glas), \\ FRACP, FICP, PJG, PPA, AM ${ }^{\mathrm{d}}$ \\ Faculty of Medicine, National University of Singapore
}

In the management of infantile gastroenteritis, the use of oral rehydration therapy is the mainstay of the treatment for dehydration except in the more severe cases. The majority of the oral solutions are mixtures

-Lecturer, Department of Physiology.

benior Lecturer, Department of Paediatrics.

'Associate Professor, Department of Paediatrics.

${ }^{\circ}$ Senior Professor and Head of the Department of Paediatrics.

\section{Acknowledgement}

We thank Miss Heng Ye Yong for technical assistance and Miss Fannie Chan for preparing the manuscript.

Address for correspondence: Dr T. F. Ho, Department of Physiology, Faculty of Medicine, National University of Singapore, Kent Ridge, Singapore 0511, Republic of Singapore. of sugar and electrolytes and the use of glucose and sucrose as the two common sugars has been extensively studied. ${ }^{1-3}$ While the use of sugar-electrolyte solutions has been well established, the dangers of hyperosmolality cannot be overlooked. ${ }^{4}$ Rice water, although not entirely new, ${ }^{5}$ has been evaluated and found to be an effective, cheap and simple means of treating infantile gastroenteritis. ${ }^{6.7}$

We aim to study the differences in osmolality between rice water, dextrose-saline solution and formula milk, all of which are used as oral therapy in some form or another in the management of infantile gastroenteritis.

\section{Materials and Methods}

Twenty samples of rice water were collected from the Paediatric ward of the University Department of Paediatrics, Singapore General Hospital over a 